Article

\title{
The Influence of Accelerated UV-A and Q-SUN Irradiation on the Antimicrobial Properties of Coatings Containing ZnO Nanoparticles
}

\author{
Małgorzata Mizielińska *, Łukasz Łopusiewicz, Monika Mężyńska and Artur Bartkowiak \\ Center of Bioimmobilisation and Innovative Packaging Materials, Faculty of Food Sciences and Fisheries, \\ West Pomeranian University of Technology Szczecin, Janickiego 35, Szczecin 71-270, Poland; \\ lukasz.lopusiewicz@zut.edu.pl (Ł.Ł.); monika.mezynska@zut.edu.pl (M.M.); artur.bartkowiak@zut.edu.pl (A.B.) \\ * Correspondence: malgorzata.mizielinska@zut.edu.pl; Tel.: +48-91-449-6132
}

Received: 10 August 2017; Accepted: 13 September 2017; Published: 17 September 2017

\begin{abstract}
The influence of accelerated UV-A and Q-SUN irradiation on the antimicrobial properties of coatings containing $\mathrm{ZnO}$ nanoparticles was investigated using a polyethylene (PE) film covering. The results of the study showed that Methyl Hydroxypropyl Celluloses (MHPC) coatings did not influence the growth of S. aureus, B. cereus, E. coli, P. aeruginosa or C. albicans cells. MHPC coatings containing $\mathrm{ZnO}$ nanoparticles inhibited the growth of bacterial strains and reduced the number of C. albicans strains. Accelerated Q-SUN and UV-A irradiation had no influence on the antimicrobial effect of nano $\mathrm{ZnO}$ coatings against S. aureus, B. cereus and E. coli. Q-SUN irradiation decreased the activity of MHPC coatings containing nanoparticles against $P$. aeruginosa and $C$. albicans. An FT-IR analysis clearly showed that ZnO nanoparticles shielded the MHPC coating during Q-SUN irradiation.
\end{abstract}

Keywords: coatings; $\mathrm{ZnO}$ nanoparticles; antibacterial; antimicrobial properties

\section{Introduction}

The use of active antimicrobial compounds incorporated in packaging material has begun to receive more attention, for its use as control agents against bacteria in food packaging systems. It can ensure microbial food safety for the consumer, and be invaluable for the extension of product shelf life [1-3]. The contact between active materials and food, which has the ability to change food's composition or the atmosphere around it, represents an active packaging system that inhibits the growth of microorganisms present on the surface of food products [1,2,4]. Zinc Oxide ( $\mathrm{ZnO})$ nanoparticles have been explored as antimicrobial agents, used in active food packaging systems, as one of five various zinc compounds that are regarded as being safe (GRAS) by the United States food and drug administration (USFDA, 21CFR182.8991) [1,2,5]. Zinc Oxide nanoparticles offer bactericidal effects for Gram-positive and Gram-negative bacteria, to spores that are resistant to high temperature, high pressure [6-8], yeasts and moulds [9]. Zinc Oxide nanoparticles have been added to petroleum-derived polymers such as LDPE, PP, PU or PET using conventional incorporation methods, such as melt mixing or solvent casting, as well as being added to biodegradable polymers such as PHA [10]. The nanoparticles were also introduced into polymer coating layers, in the application of antimicrobial packaging [2,11]. Numerous studies have shown an increase in the shelf life of food products packed in films containing $\mathrm{ZnO}$ nanoparticles (within a polymer matrix), or used with coatings containing $\mathrm{ZnO}$ nanoparticles [9,12-15]. The shelf life of sliced wheat bread was extended from 3 to 35 days using packaging containing nanoparticles, as compared to control versions. All active coatings reduced the number of yeasts and moulds in sliced bread for 15 days, and offered a further improvement in antimicrobial properties obtained for active coatings, with no fungal growth over 
a 15-day period [9]. Films containing nano-ZnO exhibited excellent antimicrobial activity and were fabricated into packaging pouches for raw meat. The prepared pouches showed significant action against microbes in the raw meat, owing to their complete inhibition of microbial growth, to the sixth day of storage at $4^{\circ} \mathrm{C}$ [12].

Polyethylene (PE) is widely used in food packaging due to its flexibility, transparency, thermo stability and low cost [16]. To create antimicrobial properties, PE films can be covered with active coatings containing $\mathrm{ZnO}$ nanoparticles [2,3]. In general, an active packaging material should function during storage to inhibit bacterial, yeast, and mould growth to extend the shelf life of the food product. This means that coatings should offer sufficient resistance against ultraviolet (UV) radiation or be shielded against UV. Ultraviolet radiation is a part of the non-ionizing region of the electromagnetic spectrum, which comprises approximately $8-9 \%$ of total solar radiation. It can lead to a degradation in the physico-mechanical, optical and antimicrobial properties of materials. Introducing an active substance that is sensitive to UV in a coating carrier can lead to an inactivation of the coating after UV-aging. Introducing an active substance that is resistant to UV in a coating carrier, or adding a substance with shielding properties, can prevent an inactivation of the coating after UV-aging. The rapid development of nanotechnology has resulted in the implementation of $\mathrm{ZnO}$ nanoparticles in coatings, to enhance the properties of such coatings without a significant influence on their transparency. Additionally, nanoparticles have attracted great interest, and the development of coating applications as agents to improve anticorrosion properties has increased, particularly as UV absorbers. It was shown that $\mathrm{ZnO}$ nanoparticles exhibited superior chemical stability under UV radiation, compared to other organic UV absorbers. The application of nanoparticles can improve UV-shielding of any respective packaging film materials. Nano-ZnO particles can even protect their own antimicrobial properties [17-20].

The purpose of this research was to study the influence of accelerated UV-A and Q-SUN irradiation (UV-aging) on the antimicrobial properties of coatings containing $\mathrm{ZnO}$ nanoparticles.

\section{Results}

\subsection{Antimicrobial Properties}

The results of the study showed that MHPC coatings did not have an influence on the growth of $S$. aureus cells, as was indicated by a previous study [2]. The MHPC coatings containing ZnO nanoparticles inhibited the growth of $S$. aureus. The accelerated Q-SUN and UV-A irradiation did not influence the antimicrobial properties of the coatings with nano-ZnO. In the case of MHPC coatings devoid of nanoparticles, the number of bacterial cells increased for films that were irradiated with UV-A (Figure 1). An increase in the number of the S. aureus was observed from $2.53 \times 10^{3}$ to $3.90 \times 10^{3}(\mathrm{CFU} / \mathrm{mL})$. Statistical analysis showed that the increase in the number of bacterial cells was not significant $(p>0.05)$.

The susceptibility assay of $B$. cereus with respect to the active coatings containing nano- $\mathrm{ZnO}$ is shown in Figure 2. The results of this research determined that MHPC coatings were not found to be active against bacteria. The $B$. cereus cells exhibited sensitivity towards coatings containing $\mathrm{ZnO}$ nanoparticles. Q-SUN and UV-A irradiation did not deactivate the antimicrobial properties of coatings with nano-ZnO. An increase in the number of bacterial cells for MHPC coatings irradiated with UV-A was observed. The differences between the numbers of viable cells were significant, as confirmed by a Duncan test $(p<0.01)$. 


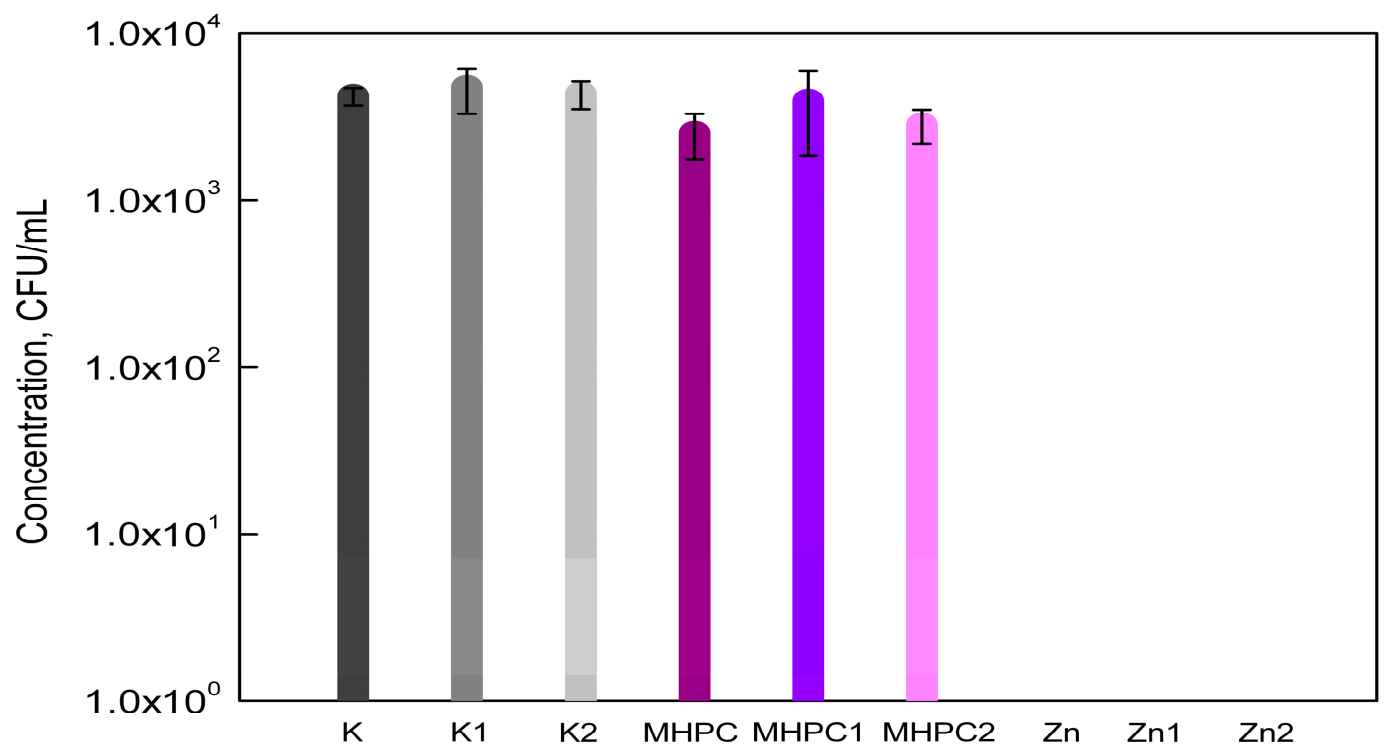

Figure 1. The influence of coatings on $S$. aureus growth. K-PE film; K1-UV-A irradiated PE film; K2-Q-SUN irradiated PE film; MHPC-PE film, covered with MHPC coating; MHPC1-UV-A irradiated PE film, covered with MHPC coating; MHPC2 Q-SUN irradiated PE film, covered with MHPC coating; Zn-PE film, covered with MHPC coating, containing ZnO nanoparticles; Zn1-UV-A irradiated PE film, covered with MHPC coating, containing ZnO nanoparticles; Zn2 Q-SUN irradiated PE film, covered with MHPC coating, containing $\mathrm{ZnO}$ nanoparticles.

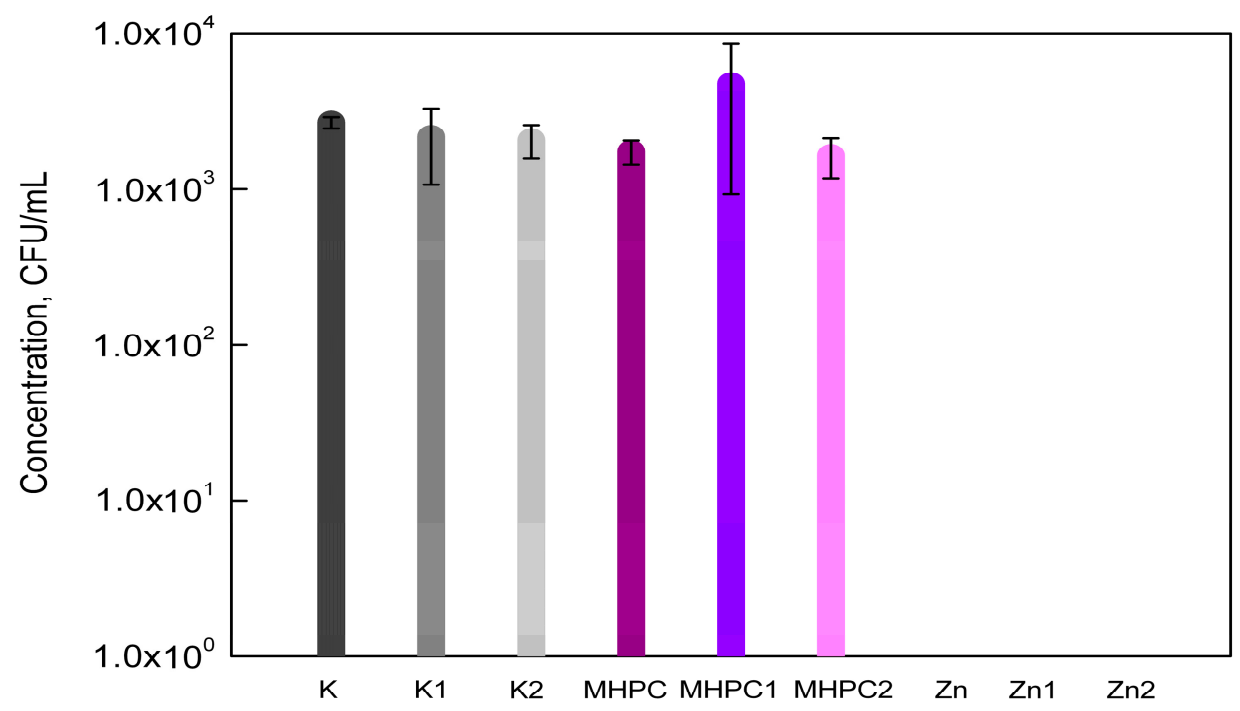

Figure 2. The influence of coatings on B. cereus growth.

The results of this research demonstrated that MHPC coatings had no influence on the growth of E. coli cells. These results were confirmed by a previous study [2]. The growth of bacterial cells after $24 \mathrm{~h}$ contact with MHPC coatings containing $\mathrm{ZnO}$ nanoparticles was not observed. As emphasised below [Figure 3], the influence of accelerated Q-SUN and UV-A irradiation on the antimicrobial properties of coatings with nano $\mathrm{ZnO}$ was also not seen. The statistical analysis demonstrated that the differences between numbers of $E$. coli cells were not significant $(p>0.05)$. 


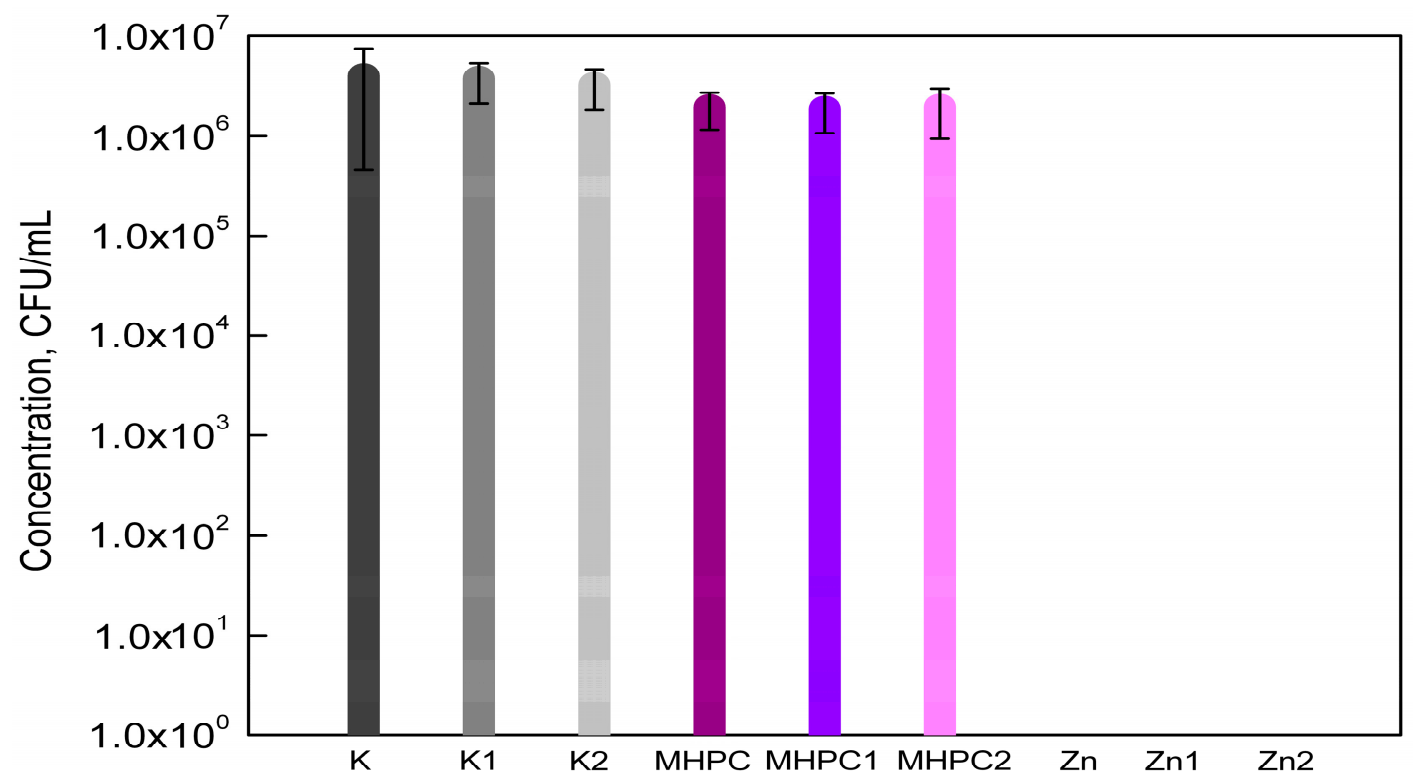

Figure 3. The influence of coatings on E. coli growth.

It was demonstrated in this study that MHPC coatings did not decrease the growth of P. aeruginosa strain $(p>0.05)$. Zinc Oxide nanoparticles as an additive to the coating completely inhibited the growth of bacterial cells. As can be seen in Figure 4, UV-A irradiation did not influence the antimicrobial properties of coatings with nano-ZnO. As previously shown, Q-SUN irradiation decreased the activity of the MHPC coatings containing nanoparticles. The growth of P. aeruginosa was observed, but the number of bacterial cells was more reduced than in the case of PE films devoid of coating, or MHPC coating devoid of nano-ZnO. It was observed that the number of $P$. aeruginosa cells decreased from $1.70 \times 10^{5}(\mathrm{~K} 2)$ and $1.81 \times 10^{5}(\mathrm{MHPC} 2)$ to $2.75 \times 10^{2}(\mathrm{CFU} / \mathrm{mL})(\mathrm{Zn} 2)$. As indicated by statistical analysis, the decrease in the number of bacterial cells was significant $(p<0.01$-differences between $\mathrm{K} 2$ and Zn2; and between MHPC2 and Zn2).

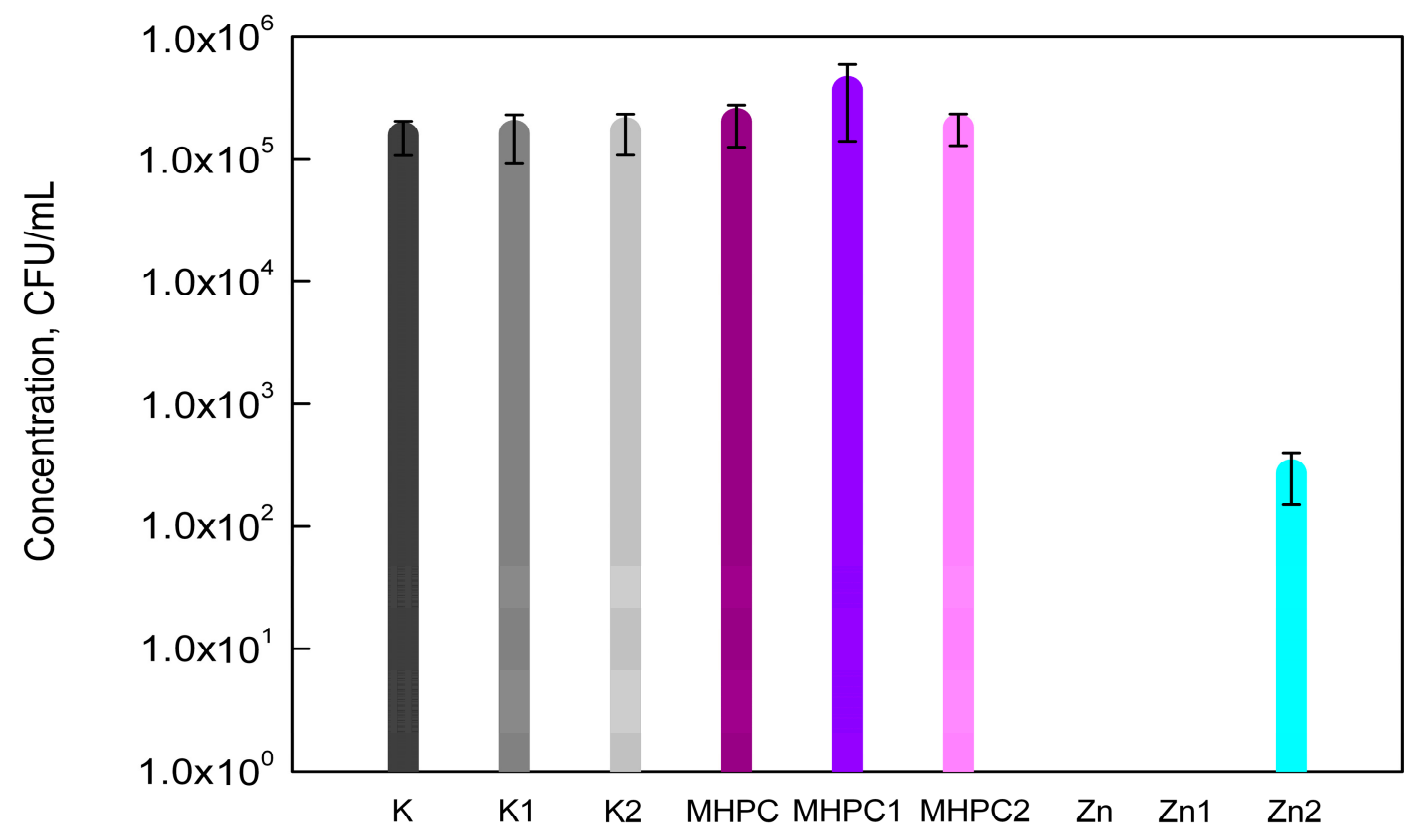

Figure 4. The influence of coatings on P. aeruginosa growth. 
The results of this study showed that MHPC coatings did not influence the growth of C. albicans cells, compared to PE films that were not covered. The MHPC coatings containing ZnO nanoparticles reduced the growth of viable cells. It was determined that the number of $C$. albicans cells decreased from $1.23 \times 10^{4}(\mathrm{~K})$ and from $1.42 \times 10^{4}(\mathrm{MHPC})$ to $1.88 \times 10^{3}(\mathrm{CFU} / \mathrm{mL})$. A Duncan's test confirmed that the influence of nano-ZnO on antimicrobial properties of $(\mathrm{K}) \mathrm{PE}$ films $(p<0.001)$ or PE films covered with MHPC $(p<0.001)$ was significant. It was shown [21] that zinc is effective in inhibiting the growth of $C$. albicans. It would appear that nanoparticle size and shape play a vital role in antimicrobial activity. The cellular membranes in the microorganism cells contain pores with a diameter measured in nanometers. Considering that nanoparticles are smaller than the microorganism pores, they have the unique property of crossing the cell membrane without hindrance [22,23]. Accelerated UV-A irradiation had no influence on the antimicrobial properties of coatings with nano-ZnO (Figure 5). This was confirmed by a Duncan test $(p>0.05)$. A log reduction of the number of $C$. albicans cells was also noted. A decrease in the number of viable cells was observed for coating with nanoparticles irradiated with Q-UV. It was shown that Q-UV irradiation had a clear influence, decreasing the antimicrobial properties of the coating. The decrease in antimicrobial activity was significant $(p<0.001)$.

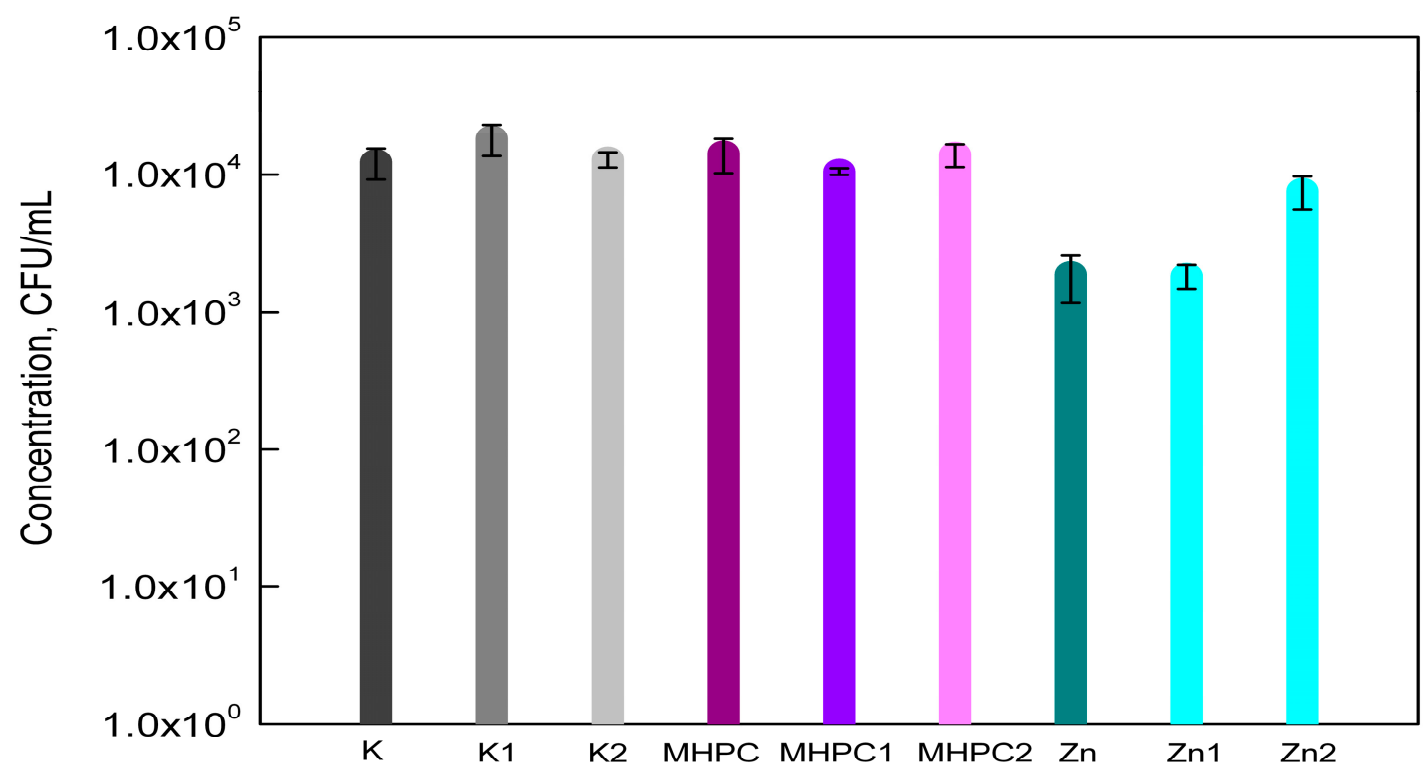

Figure 5. The influence of coatings on C. albicans growth.

\subsection{FT-IR Analysis}

The influence of UV irradiation and Q-SUN irradiation on coatings can be clearly noted using Fourier transform infrared (FT-IR) spectroscopy. The properties that influence the absorption peak and band positions are the structure, the chemical composition, and the morphology of thin films [17]. The results of this study demonstrated that differences in chemical composition and morphology of PE films (K) after UV-A irradiation (K1) and Q-SUN irradiation (K2) were not found. The results indicated that accelerated irradiation had no effect on PE film samples. The influence of UV-A irradiation on MHPC (MHPC1) or MHPC coatings containing ZnO nanoparticles (Zn1) was also not observed. A MHPC coating (MHPC), a Q-SUN irradiated MHPC coating (MHPC2) and a Q-SUN irradiated MHPC coating with $\mathrm{ZnO}$ nanoparticles $(\mathrm{Zn} 2)$ are presented in Figure 6. There are four regions viewed in the FT-IR spectroscopy, extending between (1) ranges from 3600 to $3200 \mathrm{~cm}^{-1}$; (2) ranges from 3200 to $2800 \mathrm{~cm}^{-1}$; (3) ranges from 1800 to $1600 \mathrm{~cm}^{-1}$ and (4) ranges from 1600 to $1400 \mathrm{~cm}^{-1}$. In the case of a $3453.68 \mathrm{~cm}^{-1}$ peak, a peak consistency with absorption can be noted, stimulated by $\mathrm{O}-\mathrm{H}$ single bonds. Alternatively, spectra peaks at 2913.35, 2846.12 and $1462.07 \mathrm{~cm}^{-1}$, can be observed for a peak with $\mathrm{CH}_{3}-\mathrm{CH}_{2}$ induced absorption. Different peak properties were shown, ranging from $1800 \mathrm{~cm}^{-1}$ to 
$1600 \mathrm{~cm}^{-1}$. A $1727.00 \mathrm{~cm}^{-1}$ peak was not observed in the case of the MHPC coating. The presence of this peak for a Q-SUN irradiated MHPC coating was noted, simulated by $\mathrm{C}=\mathrm{O}$ double bonds. It was clearly proven that accelerated Q-SUN irradiation altered the chemical composition of the MHPC layer. A $1727.00 \mathrm{~cm}^{-1}$ peak was not observed for Q-SUN irradiated MHPC coatings containing ZnO nanoparticles. It is tempting to suggest that nano-ZnO shielded the MHPC layer against Q-SUN irradiation. This conclusion was indicated by El-Feky O.M. et al. [19] who used ZnO nanoparticles as an additive for a coating created for oil paints on paper, to protect them against UV irradiation.

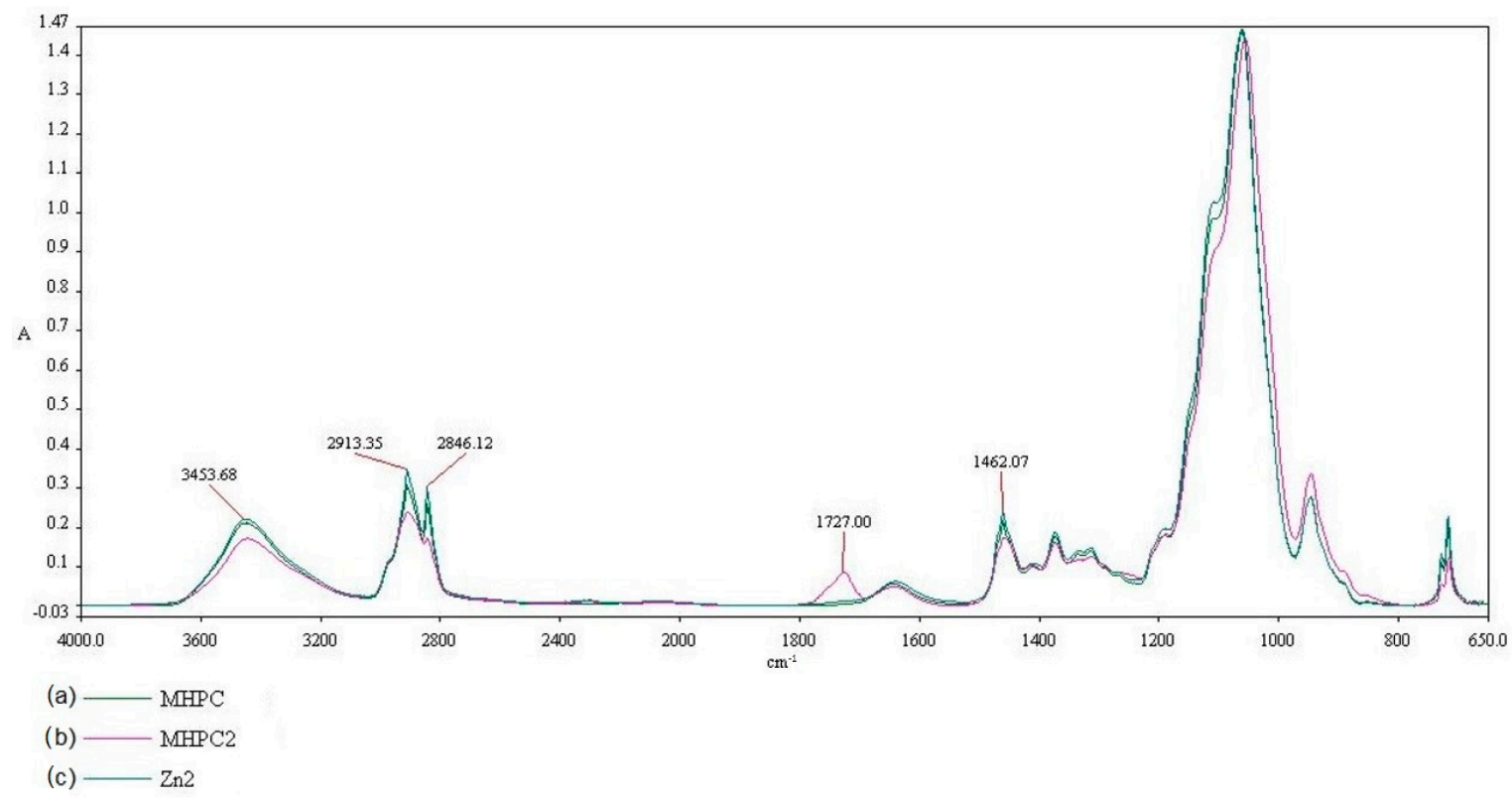

Figure 6. The FT-IR spectra of (a) MHPC coating (b) Q-SUN irradiated MHPC coating and (c) Q-SUN irradiated MHPC coating with $\mathrm{ZnO}$ nanoparticles

\subsection{Scanning Electron Microscopy (SEM)}

Scanning electron microscopy (SEM) is the most widely applied technique to characterize the shape, size, morphology, and porosity of matrices [17]. Figure 7 shows SEM images of coatings containing $\mathrm{ZnO}$ nanoparticles. SEM images revealed that $\mathrm{ZnO}$ nanoparticles were homogeneously distributed throughout the coating surfaces. Differences between the control coating and the irradiated coatings were not observed.

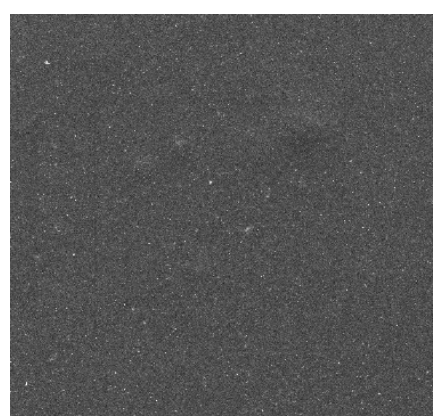

(a)

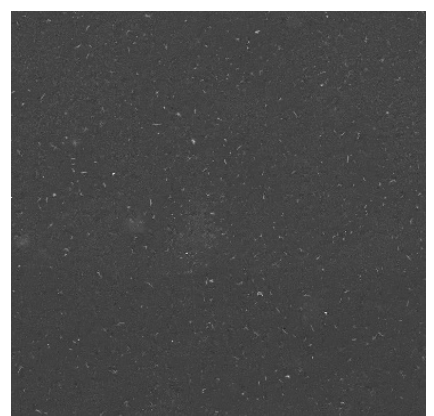

(b)

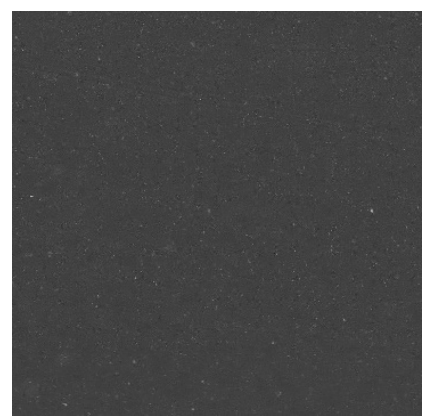

(c)

Figure 7. The SEM images of (a) MHPC coating (b) Q-SUN irradiated MHPC coating and (c) Q-SUN irradiated MHPC coating with $\mathrm{ZnO}$ nanoparticles. 


\section{Discussion}

Nano-Zinc Oxide $(\mathrm{ZnO})$ particles exhibit many advantages, such as low cost, UV blocking properties and a white appearance [2,20]. Moreover, many studies have indicated a highly specific toxicity of zinc oxide nanoparticles against bacteria, yeast, moulds, and a non-toxicity to human cells [24]. El-Feky O.M. et al. [19] introduced $\mathrm{ZnO}$ nanoparticles into a coating for oil paints on paper, which protected them against UV aging and microbial attack. Regarding antifungal activity, $\mathrm{ZnO}$ nanoparticles showed significant antifungal activity against some fungal strains, such as Aspergillus flavus, A. niger and Candida albicans. Previous studies [2] have demonstrated that $\mathrm{ZnO}$ nanoparticles can be introduced into MHPC coatings to cover packaging materials. It has been shown that active coatings exhibited antimicrobial activity against $S$. aureus and $E$. coli cells, when the growth of the strains was not observed. The goal of our research was to investigate the antimicrobial properties of MHPC coatings with nano-ZnO against B. cereus, Pseudomonas aeruginosa and Candida albicans. The influence of UV-aging on antimicrobial properties and the capability of ZnO nanoparticles to protect their own viability were also examined. The results were indicated by a previous study [2] and by Venkatesan R. et al. [25], who indicated that films containing $\mathrm{ZnO}$ nanoparticles were highly active in killing E. coli as Gram-negative and S. aureus as Gram-positive cells. The antibacterial activity of coatings with nano-ZnO was indicated against both E. coli and B. atrophaeus [26]. Aysa N.H. [27] showed antimicrobial properties of $\mathrm{ZnO}$ nanoparticles against $P$. aeruginosa. The results of the study did not show any difference between the sensitivity of Gram-positive and Gram-negative bacteria towards non-irradiated coatings containing $\mathrm{ZnO}$ nanoparticles. The results shown here are not comparable with those reported by Sharma D. et al. [28], who exhibited greater antibacterial activity against E. coli bacterium than against S. aureus. Sinha R. et al. [29] and Zhang H. et al. [11] indicated that the nanotoxicity of $\mathrm{ZnO}$ nanoparticles was more pronounced on Gram-negative bacteria than on Gram-positive. The opposite results were obtained by Esmailzadeh H. et al. [16] and Gandhi R.R. et al. [30], who indicated that Gram-positive bacteria were more sensitive to $\mathrm{ZnO}$ nanoparticles than Gram-negative bacteria were. It is tempting to suggest that the greater sensitivity of Gram-positive compared to Gram-negative bacteria to $\mathrm{ZnO}$ nanoparticles is due to differences in cell membrane structure. The cell membrane of the Gram-negative bacteria is composed of lipids, proteins and lipopolysaccharides, whereas the Gram-positive bacteria do not contain lipopolysaccharides and cannot provide effective protection [24,31,32]. Moreover, the small sized ZnO nanoparticles could also permeate the bacterial cell and combine with intracellular DNA and RNA molecules to block genome replication [33]. The suggested mechanism for the antibacterial activity of ZnO nanoparticles is based mainly on the formation of reactive oxygen species (ROS) from water and oxygen [34], which disrupt the integrity of the bacterial membrane-although additional mechanisms have also been suggested.

\section{Materials and Methods}

\subsection{Materials}

The test microorganisms used in this study were obtained from a collection from the Leibniz Institute DSMZ (Deutsche Sammlung von Mikroorganismen und Zellkulturen). The strains were supplied from an American Type Culture Collection (ATCC). The organisms used in this study were S. aureus strain DSMZ 346, B. cereus ATCC 14579, E. coli DSMZ 498, P. aeruginosa ATCC 27853 and C. albicans DSMZ 2566.

Polyethylene films, (A4, $50 \mu \mathrm{m})(\mathrm{KB}$ FOLIE) were used in this research. MHPC (Chempur, Piekary Ślaskie, Poland) was used as coating carrier. Zinc Oxide AA $44899,(\sim 70 \mathrm{~nm})$ was used as an active substance. To verify the antimicrobial properties of any coatings, TSB, TSA and Sabouraud mediums (Merck, Darmstadt, Germany) were used. All mediums were prepared according to the Merck protocol (all mediums were weighed according to the manufacturer's instructions, suspended in $1000 \mathrm{~mL}$ of distilled water, and autoclaved at $121^{\circ} \mathrm{C}$ for $\left.15 \mathrm{~min}\right)$. 


\subsection{Coating Preparation and Antimicrobial Properties Analysis}

(1) $4 \mathrm{~g}$ of MHPC was introduced into $100 \mathrm{~mL}$ of water. The mixture was mixed for $1 \mathrm{~h}$ using a magnetic stirrer (Ika) at $1500 \mathrm{rpm}$. The mixture was used to cover the PE films to obtain coatings devoid of any active substances.

(2) $0.082 \mathrm{~g}$ of $\mathrm{ZnO}$ nanoparticles was introduced into $50 \mathrm{~mL}$ of water. As a first step, the mixture was mixed for $1 \mathrm{~h}$ using a magnetic stirrer $(450 \mathrm{rpm})$. Next, the mixture was sonicated (sonication parameters: cycle: 0.5 ; amplitude: $20 \%$; time: $10 \mathrm{~min}$ ), while at the same time, the second mixture ( $4 \mathrm{~g}$ of MHPC into $50 \mathrm{~mL}$ ) was prepared as described above. The $\mathrm{ZnO}$ nanoparticles solution was introduced into the MHPC mixture and sonicated (sonication parameters: cycle: 0.5; amplitude: 20\%; time: $10 \mathrm{~min})$.

Polyethylene (PE) films were covered using Unicoater 409 (Erichsen, Hemer, Germany) at a temperature of $25{ }^{\circ} \mathrm{C}$ with a roller at a diameter of $40 \mu \mathrm{m}$. The coatings were dried for $10 \mathrm{~min}$ at a temperature of $50{ }^{\circ} \mathrm{C}$. $1.6 \mathrm{~g}$ layers of MHPC per $1 \mathrm{~m}^{2}$ of PE were obtained. The active coatings contained $0.032 \mathrm{~g}$ of $\mathrm{ZnO}$ AA 44,899 particles per $1 \mathrm{~m}^{2}$ of PE film. PE films that were not covered were control samples (K). PE films with MHPC coatings were also used as control samples (MHPC).

The film samples were cut into square shapes $(3 \mathrm{~cm} \times 3 \mathrm{~cm})$. The antimicrobial properties of non-covered and covered films were carried out according to ASTM E 2180-01 standard [35].

\subsection{Accelerated Irradiation}

The non-covered and covered film samples were cut into rectangle shapes $(23.5 \mathrm{~cm} \times 7.0 \mathrm{~cm}$ and $26.0 \mathrm{~cm} 2.5 \mathrm{~cm}$ ) respectively. The samples were introduced into a UV-A accelerated weathering tester with $1.55 \mathrm{~W} / \mathrm{m}^{2}$ (QUV/spray, Q-LAB) and into Q-SUN accelerated Xenon Test Chamber with $1.5 \mathrm{~W} / \mathrm{m}^{2}$ (Model Xe-2, Q-LAB) and irradiated $24 \mathrm{~h} \mathrm{[36].}$

\subsection{FT-IR}

Fourier transform infrared (FT-IR) spectrum of the non-covered and covered film samples was measured using a FT-IR spectroscopy (Perkin Elmer Spectrophotometer, Spectrum 100, Waltham, MA, USA), operated at a resolution of $4 \mathrm{~cm}^{-1}$, over four scans. Film samples were cut into square shapes $(2 \mathrm{~cm} \times 2 \mathrm{~cm})$ and placed directly at the ray-exposing stage. The spectrum was recorded at a wavelength of $650-4000 \mathrm{~cm}^{-1}$.

\subsection{SEM}

A microscopic analysis was performed using a microscope Vega 3 LMU (Tescan, Brno-Kohoutovice, Czech Repuplic) scanning electron microscope (SEM). The tests were necessary to determine the influence of accelerated irradiation on the coatings. An analysis was performed at room temperature with tungsten filament, and an accelerating voltage of $20 \mathrm{kV}$ was used to capture SEM images for both the non-covered and covered films. All specimens were viewed from above.

\subsection{Statistical Analysis}

The statistical significance was determined using an analysis of variance (ANOVA) followed by a Duncan's test. The values were considered as significantly different when $p<0.05$. All analyses were performed with Statistica version 10 (StatSoft Polska, Kraków, Poland).

Acknowledgments: Research funded by the West Pomeranian University of Technology Szczecin

Author Contributions: Ma.Mi. conceived and designed the experiments, and wrote the paper; Ma.Mi. and L.L. performed the microbiological tests and analyzed the data; L.L. performed FT-IR tests and analyzed the data, Mo.Me. performed SEM tests and analyzed the data; Ma.Mi. and L.L. prepared reagents/materials; Mo.Me. and L.L. contributed analysis tools; A.B. performed statistical analysis and analyzed the data.

Conflicts of Interest: The authors declare no conflict of interest. 


\section{References}

1. Akbar, A.; Anal, A.K. Zinc oxide nanoparticles loaded active packaging, a challenge study against Salmonella typhimurium and Staphylococcus aureus in readyto-eat poultry meat. Food Control 2014, 38, 88-95. [CrossRef]

2. Mizielińska, M.; Lisiecki, S.; Jotko, M.; Chodzyńska, I.; Bartkowiak, A. The antimicrobial properties of polylactide films covered with $\mathrm{ZnO}$ nanoparticles-containing layers. Przem. Chem. 2015, 94, 1000-1003.

3. Bartkowiak, A.; Mizielińska, M.; Sumińska, P.; Romanowska-Osuch, A.; Lisiecki, S. Innovations in food packaging materials. In Emerging and Traditional Technologies for Safe, Healthy and Quality Food; Nedovic, V., Raspor, P., Lević, J., Tumbas, V., Barbosa-Canovas, G.V., Eds.; Springer: Berlin, Germany, 2016.

4. Jafarzadeh, S.; Alias, A.K.; Ariffin, F.; Mahmud, S.; Najafi, A.; Ahmad, M. Fabrication and characterization of novel semolina-based antimicrobial films derived from the combination of $\mathrm{ZnO}$ nanorods and nanokaolin. J. Food Sci. Technol. 2017, 54, 105-113. [CrossRef] [PubMed]

5. Wang, Y.; Ma, J.; Xu, Q.; Zhang, J. Fabrication of antibacterial casein-based ZnO nanocomposite for flexible coatings. Mat. Design. 2017, 113, 240-245. [CrossRef]

6. Dizaj, S.M.; Lotfipour, F.; Barzegar-Jalali, M.; Zarrintan, M.H.; Adibkia, K. Antimicrobial activity of the metals and metal oxide nanoparticles. Mat. Sci. Eng. 2014, 44, 278-284. [CrossRef] [PubMed]

7. Oprea, A.E.; Pandel, L.M.; Dumitrescu, A.M.; Andronescu, E.; Grumezescu, V.; Chifiriuc, M.C.; Mogoantă, L.; Bălşeanu, T.-A.; Mogoşanu, G.D.; Socol, G.; et al. Bioactive ZnO Coatings Deposited by MAPLE-An Appropriate Strategy to Produce Efficient Anti-Biofilm Surfaces. Molecules 2016, 21, 220. [CrossRef] [PubMed]

8. Azizi, S.; Ahmad, M.B.; Hussein, M.Z.; Ibrahim, N.A. Synthesis, Antibacterial and Thermal Studies of Cellulose Nanocrystal Stabilized ZnO-Ag Heterostructure Nanoparticles. Molecules 2013, 18, 6269-6280. [CrossRef] [PubMed]

9. Noshirvani, N.; Ghanbarzadeh, B.; Mokarram, R.R.; Hashemi, M. Novel active packaging based on carboxymethyl cellulose-chitosan-ZnO NPs nanocomposite for increasing the shelf life of bread. Food Packag. Shelf Life 2017, 11, 106-114. [CrossRef]

10. Castro-Mayorgaa, J.L.; Fabraa, M.J.; Pourrahimib, A.M.; Olssonb, R.T.; Lagarona, J.M. The impact of zinc oxide particle morphology as anantimicrobial and when incorporated inpoly(3-hydroxybutyrate-co3-hydroxyvalerate)films for food packaging and food contact surfacesapplications. Food Bioprod. Process. 2017, 101, 32-44. [CrossRef]

11. Zhang, H.; Hortal, M.; Jordá-Beneyto, M.; Rosa, E.; Lledo, M.L.; Lorente, I. ZnO-PLA nanocomposite coated paper for antimicrobial packaging application. Food Sci. Technol. 2017, 78, 250-257. [CrossRef]

12. Rahman, P.M.; Mujeeb, V.M.A.; Muraleedharan, K. Flexible chitosan-nano ZnO antimicrobial pouches as a new material for extending the shelf life of raw meat. Int. J. Biol. Macromol. 2017, 97, 382-391. [CrossRef] [PubMed]

13. Espita, P.J.P.; Soares, N.F.F.; Coimbra, J.S.R.; de Andrade, N.J.; Medeiros, E.A.A. Zinc Oxide Nanoparticles: Synthesis, Antimicrobial Activity and Food Packaging Applications. Food Bioprocess Technol. 2012, 5, 1447-1464. [CrossRef]

14. Al-Naamani, L.; Dobretsov, S.; Dutta, J. Chitosan-zinc oxide nanoparticle composite coating for active food packaging applications. Innov. Food Sci. Emerg. Technol. Part A 2016, 38, 231-237. [CrossRef]

15. Dhapte, V.; Gaikwad, N.; More, P.V.; Banerjee, S.; Dhapte, V.V.; Kadam, S.; Khanna, P.K. Transparent $\mathrm{ZnO} /$ polycarbonate nanocomposite for food packaging applications. Nanocomposites 2015, 1, 106-112. [CrossRef]

16. Esmailzadeh, H.; Sangpour, P.; Shahraz, F.; Hejazi, J.; Khaksar, R. Effect of nanocomposite packaging containing $\mathrm{ZnO}$ on growth of Bacillus subtilis and Enterobacter aerogenes. Mat. Sci. Eng. 2016, 58, 1058-1063. [CrossRef] [PubMed]

17. Nguyena, T.V.; Dao, P.H.; Khanh Linh Duong, K.L.; Duong, Q.H.; Vu, Q.T.; Nguyena, A.H.; Mac, V.P.; Lea, T.L. Effect of $\mathrm{R}^{-\mathrm{TiO}_{2}}$ and $\mathrm{ZnO}$ nanoparticles on the UV-shielding efficiency of water-borne acrylic coating. Prog. Org. Coat. 2017, 110, 114-121. [CrossRef]

18. Marvizadeh, M.M.; Oladzadabbasabadi, N.; Nafchi, A.M.; Jokar, M. Preparation and characterization of bionanocomposite film based on tapioca starch/bovine gelatin/nanorod zinc oxide. Int. J. Biol. Macromol. 2017, 99, 1-7. [CrossRef] [PubMed] 
19. El-Feky, O.M.; Hassan, E.A.; Fadel, S.M.; Hassan, M.L. Use of ZnO nanoparticles for protecting oil paintings on paper support against dirt, fungal attack, and UV aging. J. Cult. Herit. 2014, 15, 165-172. [CrossRef]

20. Kairyte, K.; Kadys, A.; Luksiene, Z. Antibacterial and antifungal activity of photoactivated ZnO nanoparticles in suspension. J. Photochem. Photobiol. Biol. 2013, 128, 78-84. [CrossRef] [PubMed]

21. Iconaru, S.L.; Prodan, A.M.; Buton, N.; Predoi, D. Structural Characterization and Antifungal Studies of Zinc-Doped Hydroxyapatite Coatings. Molecules 2017, 22, 604. [CrossRef] [PubMed]

22. Gunalan, S.; Sivaraj, R.; Rajendranb, V. Green synthesized ZnO nanoparticles against bacterial and fungal pathogens. Prog. Nat. Sci. 2012, 22, 693-700. [CrossRef]

23. Stanković, A.; Dimitrijević, S.; Uskoković, D. Influence of size scale and morphology on antibacterial properties of $\mathrm{ZnO}$ powders hydrothemally synthesized using different surface stabilizing agents Colloid. Surface 2013, 102, 21-28. [CrossRef] [PubMed]

24. Liu, Y.; Kim, H.I. Characterization and antibacterial properties of genipin-crosslinked chitosan/poly(ethylene glycol)/ZnO/Ag nanocomposites. Carbohyd. Polym. 2012, 89, 111-116. [CrossRef] [PubMed]

25. Venkatesan, R.; Natesan Rajeswari, N. ZnO/PBAT nanocomposite films: Investigation on the mechanical and biological activity for food packaging. Polym. Adv. Technol. 2017, 28, 20-27. [CrossRef]

26. Tam, K.H.; Djurišić, A.B.; Chan, C.M.N.; Xi, Y.Y.; Tse, C.W.; Leung, Y.H.; Chan, W.K.; Leung, F.C.C.; Au, D.W.T. Antibacterial activity of $\mathrm{ZnO}$ nanorods prepared by a hydrothermal method. Thin Solid Films 2008, 516, 6167-6174. [CrossRef]

27. Aysa, N.H.; Salman, D.H. Antibacterial activity of modified zinc oxide nanoparticles against Pseudomonas aeruginosa isolates of burn infections. World Sci. News 2016, 33, 1-14.

28. Sharma, D.; Sharma, S.; Kaitha, B.S.; Rajputa, J.; Kaur, M. Synthesis of ZnO nanoparticles using surfactant free in-air and microwave method. Appl. Surf. Sci. 2011, 257, 9661-9672. [CrossRef]

29. Sinha, R.; Karan, R.; Sinha, A.; Khare, S.K. Interaction and nanotoxic effect of ZnO and Ag nanoparticles on mesophilic and halophilic bacterial cells. Bioresour. Technol. 2011, 102, 1516-1520. [CrossRef] [PubMed]

30. Gandhi, R.R.; Gowri, S.; Suresh, J.; Sundrarajan, M. Ionic Liquids Assisted Synthesis of ZnO Nanostructures: Controlled Size, Morphology and Antibacterial Properties. J. Mater. Sci. Technol. 2013, 29, 533-538. [CrossRef]

31. Barani, H. Preparation of antibacterial coating based on in situ synthesis of $\mathrm{ZnO} / \mathrm{SiO}_{2}$ hybrid nanocomposite on cotton fabric. Appl. Surf. Sci. 2014, 320, 429-434. [CrossRef]

32. Ibãnescu, B.M.; Musat, V.; Textor, T.; Badilita, V.; Mahltig, B. Photocatalytic and antimicrobial Ag/ZnO nanocomposites for functionalization of textile fabrics. J. Alloys Comp. 2014, 610, 244-249. [CrossRef]

33. Ma, J.; Liu, J.; Bao, Y.; Zhu, Z.; Wang, X.; Zhang, J. Synthesis of large-scale uniform mulberry-like ZnO particles with microwave hydrothermal method and its antibacterial property. Ceram. Int. 2013, 39, 2803-2810. [CrossRef]

34. Gordon, T.; Perlsteina, B.; Houbara, O.; Felner, I.; Banin, E.; Margel, S. Synthesis and characterization of zinc/iron oxide composite nanoparticles and their antibacterial properties. Colloid. Surf. A 2011, 374, 1-8. [CrossRef]

35. ASTM Standard Test Method for Determining the Activity of Incorporated Antimicrobial Agent(s) in Polymeric or Hydrophobic Materials. Available online: http:/ / www.astm.org/cgi-bin/resolver.cgi?E2180-01 (accessed on 13 September 2017).

36. Nichols, M.; Boisseau, J.; Pattison, L.; Campbell, D.; Quill, J.; Zhang, J.; Smith, D.; Henderson, K.; Seebergh, J.; Berry, D.; et al. An improved accelerated weathering protocol to anticipate Florida exposure behavior of coatings. J. Coat. Technol. Res. 2013, 10, 153-173. [CrossRef]

Sample Availability: Samples of the compounds are not available. 